vol. $21-n^{\circ} 1 \mid 2005$

Femmes, genre, migration et mobilités

\title{
Les Falachas, Nègres errants du peuple juif, N'DIAYE Tidiane
}

Paris, Gallimard, 2004, 232 p. ISBN : 2-07-077135-0

\section{Gilles Ferréol}

\section{OpenEdition}

\section{Journals}

Édition électronique

URL : https://journals.openedition.org/remi/4261

DOI : 10.4000/remi.4261

ISSN : $1777-5418$

Éditeur

Université de Poitiers

Édition imprimée

Date de publication : 29 mai 2005

Pagination : 283-284

ISBN : 2-911627-39-3

ISSN : 0765-0752

\section{Référence électronique}

Gilles Ferréol, «Les Falachas, Nègres errants du peuple juif, N'DIAYE Tidiane », Revue européenne des migrations internationales [En ligne], vol. $21-\mathrm{n}^{\circ} 1$ | 2005, mis en ligne le 10 septembre 2008, consulté le 16 avril 2022. URL : http://journals.openedition.org/remi/4261 ; DOI : https://doi.org/10.4000/remi. 4261

Ce document a été généré automatiquement le 16 avril 2022.

(c) Université de Poitiers 


\section{Les Falachas, Nègres errants du peuple juif, N'DIAYE Tidiane}

Paris, Gallimard, 2004, 232 p. ISBN : 2-07-077135-0

Gilles Ferréol

\section{RÉFÉRENCE}

N'DIAYE Tidiane, Les Falachas, Nègres errants du peuple juif, Paris, Gallimard, 2004, 232 p.

ISBN : 2-07-077135-0

1 Les Falachas, ces Noirs éthiopiens se réclamant du judaïsme, constituent, encore à notre époque, une véritable énigme: "L'investigation anthropologique et historique peine à saisir bien des aspects de leur culture et des origines de leurs pratiques religieuses, qui restent pour une large part dans la pénombre, voire dans l'obscurité totale.» Exception faite des publications de Flavius Josèphe au début de l'ère chrétienne, « il n'existe aucun document [les] rattachant de manière crédible [...] à la vieille civilisation hébraïque » (p. 175).

2 Ces «hommes au visage brûlé », comme les dénommait Hérodote, ont le plus souvent été associés à «un nombre incalculable de préjugés fortement enracinés, d'idées préconçues non moins tenaces et de théories pseudo-scientifiques dépeignant un sombre tableau des peuples africains» (p. 81). Longtemps ignorés, ils ont été «découverts » pour la première fois par le rabbin Ben Abi Zimra au xvI siècle. Leurs traces furent ensuite explorées par Joseph Halévy, Jacques Faïtlovitch de son côté n'hésitant pas dans les années 1920 à faire campagne en leur faveur afin de promouvoir leur émancipation.

3 Plusieurs pistes, souligne l'auteur, peuvent être évoquées : celle de Ménélik Ier (fils du roi Salomon et de la reine de Saba) et de son escorte, celle d'une tribu perdue d'Israël, celle de l'Exode et de «Moïse, général des armées égyptiennes» ou celle - plus plausible - de descendants métissés de combattants des troupes du chancelier Beya... On estime, de nos jours, à environ 80000 le nombre de ces Juifs « déracinés ", à la fois 
« encombrants » ou "atypiques » en raison de leurs coutumes et de leur couleur de peau, ayant opté dès l'automne 1984 pour le retour (Aliyah) à Sion et à la Terre promise après de longs mois d'attente, parqués dans des camps de réfugiés au Soudan, « tels des morts vivants, épuisés, hagards et squelettiques » (p. 16).

4 Après avoir été ignorées ou rejetées pendant des décennies par les milieux officiels car perçues, à la différence d'autres minorités de la diaspora juive, comme difficilement intégrables, voire " inassimilables », ces populations ne sont plus « indésirables » et ont été à nouveau autorisées récemment à immigrer, notamment sur les territoires occupés de Palestine, l'État hébreu - est-il argué - oscillant entre l'« humanitaire » et la «manipulation médiatique » (pp. 37 et suiv.). Ce transfert, décidé par le gouvernement d'Ariel Sharon en février 2003, doit être interprété, estime N’Diaye, au regard d'enjeux démographiques et géostratégiques. L'accueil réservé à ces " convertis » est cependant loin d'être idyllique : situation précaire, marginalisation et, quelquefois, ostracisme ou injustices.

5 Qu'elle se fonde sur une notion de "race", de religion ou de rang social, la problématique identitaire apparait ainsi comme « invariablement complexe » (p. 194). Cette contribution érudite, fruit d'un long travail de recherche, nous est, à cet égard, très précieuse et attire notre attention, à travers cette communauté, sur un drame de notre temps «quasiment tabou et jusqu'à présent masqué ou escamoté » ( $4^{\mathrm{e}} \mathrm{de}$ couverture). Signalons enfin, outre une copieuse bibliographie, de riches annexes (notes, repères chronologiques, glossaire) et diverses cartes, photographies ou tableaux de synthèse.

\section{AUTEURS}

\section{GILLES FERRÉOL}

Université de Poitiers, LARESCO-ICOTEM 